\title{
CARACTERÍSTICAS AGRONÔMICAS E AVALIAÇÃO ECONÔMICA DO MILHO SOB DOSES DE NITROGÊNIO NA FORMA DE UREIA COMUM E PELETIZADA
}

\author{
Jônatas Barros dos Santos ${ }^{1}$; Alberto Nascimento Silva ${ }^{2}$; Jose de Oliveira Cruz ${ }^{3}$; Rodrigo Barros dos
} Santos $^{4}$; Ricardo Ferreira da Silva ${ }^{5}$

\section{RESUMO}

O milho é a terceira commodity em valor bruto de produção no Brasil, ficando atrás apenas da soja e da carne bovina. Apesar dos avanços tecnológicos que vem ocorrendo no meio agrícola nos últimos anos, a produtividade da cultura tem se mantido quase constante no decorrer dos anos, próximo de $2.500 \mathrm{~kg} \mathrm{ha}^{-1}$, considerado um baixo valor quando comparado a outros países. A adubação nitrogenada é fator bastante complexo para diversas culturas em razão das várias transformações que ocorrem com o $\mathrm{N}$ no solo e influenciam no seu aproveitamento pelas plantas. Objetivou-se nesse trabalho estudar o efeito da ureia comum e peletizada em diferentes doses nas características agronômicas do milho na cidade de Barreiras/BA, bem como sua avaliação econômica para a safra 2013/14. Os tratamentos foram compostos por um esquema fatorial $2 \times 3$, sendo dois tipos de ureia (ureia convencional e ureia polimerizada) com três doses de nitrogênio $(\mathrm{N})\left(75,100,125 \mathrm{~kg} \mathrm{ha}^{-1}\right)$. Foram analisadas as seguintes variáveis: altura de plantas, diâmetro de espiga, massa seca de mil grãos, estimativa de produtividade e avaliação econômica. Apenas para variável massa de mil grãos foi observado diferença significativa entre as fontes de nitrogênio. A aplicação de doses de nitrogênio influenciou diretamente a produção de milho, independente da fonte utilizada, havendo incremento de $6,50 \mathrm{~kg} \mathrm{ha}^{-1}$ de milho por cada $\mathrm{kg}$ de $\mathrm{N}$ aplicado. A dose de $75 \mathrm{~kg}$. ha- $\mathrm{da}^{-1}$ ureia comum, apresentou o melhor retorno econômico para as condições testadas.

Palavras-chave: Adubação nitrogenada, fertilidade do solo, Zea mays.

\section{AGRONOMIC CHARACTERISTICS AND ECONOMIC EVALUATION OF MAIZE UNDER NITROGEN DOSES IN THE FORM OF COMMON AND PELLET UREA}

\begin{abstract}
Corn is the third commodity producer in Brazil, second only to soybeans and beef. Despite the technological advances that have been occurring in the agricultural environment in recent years, the productivity of the crop has remained almost constant over the years, close to $2,500 \mathrm{~kg} \mathrm{ha}^{-1}$, a value considered low when compared to other countries. Nitrogen fertilization is a complex factor for several crops due to the various transformations that occur with $\mathrm{N}$ in the soil and influence its use by plants. The objective of this work was to study the effect of common and pelleted urea in different doses on the

Received 16 Jun, 2020 • Accepted 16 Out, 2020

\footnotetext{
${ }^{1}$ Mestre e Doutorando em Agronomia. Faculdade de Agronomia e Medicina Veterinária, Universidade de Brasília, Brasília/DF jonatas.bsantos@hotmail.com;

${ }^{2}$ Mestre e Doutorando em Agronomia. Faculdade de Agronomia e Medicina Veterinária, Universidade de Brasília, Brasília/DF, albertosilvaagro@gmail.com;

${ }^{3}$ Mestre e Doutorando em Agronomia. Faculdade de Agronomia e Medicina Veterinária, Universidade de Brasília, Brasília/DF, josecruz08@yahoo.com;

${ }^{4}$ Eng. Agrônomo, Faculdade São Francisco de Barreiras, 47800-970, Barreiras, Bahia, rodrigobds@ hotmail.com.br;
}

${ }^{5}$ Eng. Agrônomo, Universidade do Estado da Bahia, 47802-682, Barreiras/BA, ricardo_ferreira-10@ hotmail.com
\end{abstract}


agronomic characteristics of maize in Barreiras city, state of Bahia, as well as its economic evaluation for the 2013/14 harvest. The treatments consisted of a 2 x 3 factorial scheme, two types of urea (conventional urea and polymerized urea) with three doses of nitrogen $(\mathrm{N})\left(75,100,125 \mathrm{~kg} \mathrm{ha}^{-1}\right)$. The following variables were analyzed: plant height, ear diameter, dry weight of a thousand grains, yield estimate and economic evaluation. Only for the variable weight of a thousand grains, a significant difference was observed between nitrogen sources. The application of nitrogen doses directly influenced maize production, regardless of the source used, with an increase of $6.50 \mathrm{~kg}$ ha-1 of maize for each $\mathrm{kg}$ of $\mathrm{N}$ applied. The $75 \mathrm{~kg} \mathrm{ha}^{-1}$ dose of common urea presented the best economic return for the conditions tested.

Keywords: Nitrogen fertilization, soil fertility, Zea mays. 


\section{INTRODUÇÃO}

O milho (Zea mays L.) é uma commodity de importância mundial e vital para a segurança alimentar de muitas populações. No Brasil, é cultivado em todo o território nacional, apresentando grande importância na alimentação humana, animal e matéria prima para indústria, sendo um dos produtos agrícolas mais produzidos no país (Souza e Braga, 2004). Na safra 2019/20 a área plantada no Brasil foi de aproximadamente 18,5 milhões de hectares, produzindo 102,33 milhões de toneladas e produtividade média de $5.531 \mathrm{~kg} \mathrm{ha}^{-1}$, enquanto na região nordeste a produtividade nesta mesma safra ficou em torno de $2.616 \mathrm{~kg} \mathrm{ha}^{-1}$ (Conab, 2020).

$\mathrm{O}$ rendimento médio do milho no Brasil é baixo em decorrência de fatores ligados à fertilidade do solo, arranjo espacial de plantas, uso de genótipos e práticas de manejo inadequadas. Contudo, por conta de suas características fisiológicas, a cultura tem potencial produtivo aproximado de seis vezes à média brasileira das últimas safras, que foi em torno de $4.000 \mathrm{~kg} \mathrm{ha}^{-1}$ (Sangoi et al., 2010). Porém, a adoção de novas tecnologias e o manejo adequado da cultura tem feito com que o teto produtivo do milho esteja atualmente entre 12.000 e $18.000 \mathrm{~kg} \mathrm{ha}$ ${ }^{1}$ (Sangoi et al., 2012).

De modo geral, uma das maiores dificuldades no alcance do teto produtivo do milho está na recomendação de adubação nitrogenada, principalmente devido às transformações do $\mathrm{N}$ no solo, sua mobilidade e fatores que influem no seu aproveitamento pelas plantas, o que torna o $\mathrm{N}$ o nutriente mais estudado nessa cultura (Costa et. al., 2012).

Segundo Souza e Lobato (2004), o nitrogênio (N) macronutriente essencial para as plantas, encontra-se no solo quase que totalmente na forma orgânica que é indisponível para as plantas, sendo absorvido somente na forma inorgânica. Este elemento é absorvido principalmente na forma de nitrato $\left(\mathrm{NO}^{3-}\right)$ ou de amônio $\left(\mathrm{NH}^{4+}\right)$, sendo a primeira forma a mais frequente, além de ser exportado em grandes quantidades nas colheitas.
O uso racional da adubação nitrogenada é fundamental, não somente para aumentar a eficiência de recuperação, mas também para aumentar a produtividade da cultura e diminuir os custos de produção (Fageria et al., 2007). No Brasil, a fonte mais usada deste nutriente na adubação é a ureia $\left[\left(\mathrm{NH}_{2}\right)^{2} \mathrm{CO}\right]$ devido seu custo-benefício por unidade de nutriente, embora a mesma apresente grandes perdas por volatilização de $\mathrm{NH}^{3}$ e por lixiviação (Civardi, et al. 2011; Silva et al. 2012). Diversas tecnologias tem sido empregadas visando reduzir as perdas que ocorrem com a ureia, como o NBPT (N-(n-butil) triamida tiofosfórica) que utiliza inibidores de urease, e outros produtos que possuem diferentes polímeros em sua composição, os quais, por sua vez, promovem redução de perdas por volatilização de amônia (Frazão et al., 2014), porém, o NBPT não é produzido nacionalmente, o que onera os custos de produção.

Assim, objetivou-se nesse trabalho estudar o efeito da ureia comum e peletizada em diferentes doses no comportamento das características agronômicas da cultura do milho, bem como sua avaliação econômica.

\section{MATERIAL E MÉTODOS}

O experimento foi realizado na área experimental da Universidade do Estado da Bahia, Campus IX, localizado em Barreiras/BA, sob as condições de sequeiro no ano agrícola 2013/2014.

A área experimental localiza-se nas seguintes coordenadas: Latitude $12^{\circ} 08^{\prime} 37.3^{\prime \prime S}$ Longitude 44 ${ }^{\circ} 7^{\prime} 48.3^{\prime \prime}$, a 483 metros de altitude. O clima da região, segundo a classificação de Koppen, é Tropical Semi-úmido (AW), com temperaturas e precipitações médias anuais de 20 a $24^{\circ} \mathrm{C}$ e 1300 a $1700 \mathrm{~mm}$, respectivamente. O solo desta área é classificado como LATOSSOLO VERMELHO AMARELO distrófico (EMBRAPA, 2018). Os dados de temperatura média e precipitação pluvial durante $o$ estudo foram coletados na estação meteorológica de Barreiras/BA, e estão apresentados na Figura 1. 
Antes da instalação do experimento foram coletadas dez amostras simples de solos na profundidade de 0-20 $\mathrm{cm}$ para formar uma amostra composta, para a caracterização das propriedades químicas e físicas (Embrapa, 2018), cujos resultados foram: $\mathrm{pH}$ em $\mathrm{CaCl}_{2}=5,38 ; \mathrm{P}($ Mehlich $)=8,60 \mathrm{mg}$ $\mathrm{dm}^{-3} ; \mathrm{K}^{+}=0,36$ cmolc $\mathrm{dm}^{-3} ; \mathrm{Ca}^{2+}=2,20$ cmolc $\mathrm{dm}^{-3}$, $\mathrm{Ca}^{2+}+\mathrm{Mg}^{2+}=2,90$ cmolc $\mathrm{dm}^{-3}, \mathrm{Al}^{3+}+\mathrm{H}^{+}=2,2$ cmolc $\mathrm{dm}^{-3}, \mathrm{~T}=5,45$ cmolc $\mathrm{dm}^{-3}, \mathrm{~V}=59,62 \%$, M.O. = 2,6 dag $\mathrm{dm}^{-3}$ e uma composição granulométrica de $46,9 \%, 12,5 \%$ e $40,5 \%$ de areia, silte e argila, respectivamente.

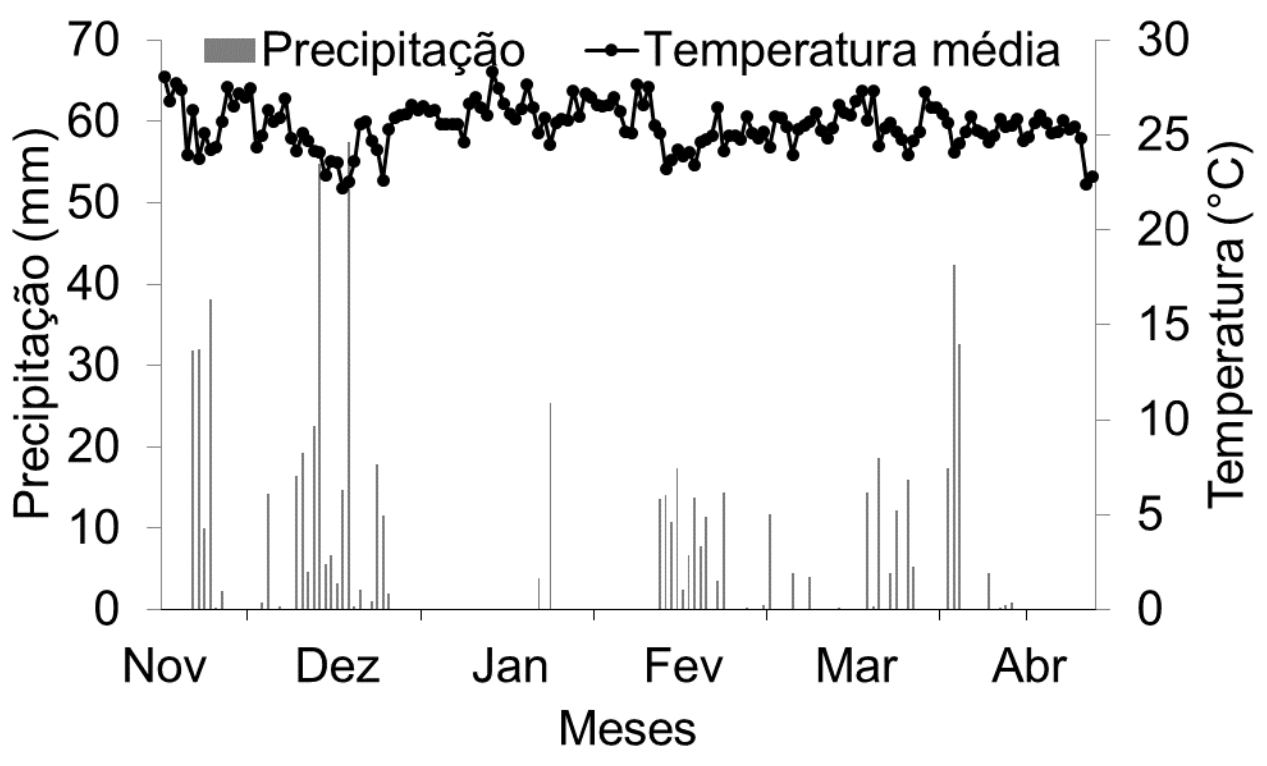

Figura 1. Dados ambientais de precipitação e temperatura média para os meses que envolveram a realização do experimento, de Dezembro/13 a Abril/14. Dados obtidos de estação automática do INMET.

De acordo com a análise, foi feita aplicação de $100 \mathrm{~kg} \mathrm{ha}^{-1}$ de $\mathrm{P}_{2} \mathrm{O}_{5}$ no sulco no momento do plantio. O plantio foi realizado em dezembro de 2013, sendo a semeadura feita manualmente, utilizando cinco sementes por metro linear e 0,80 metros entre linhas e densidade populacional correspondente a 62.500 plantas por hectare. A variedade cultivada foi a AL - Bandeirantes, de ciclo semiprecoce (130 a 140 dias) e recomendado por apresentar teor médio de produtividade, ciclo intermediário e resistência moderada às principais doenças, recomendado para solos de baixa a alta fertilidade.

O delineamento experimental foi em blocos casualizados com sete tratamentos e cinco repetições, cada parcela com $12 \mathrm{~m}^{2}$, e cinco linhas de cultivo, sendo $0,80 \mathrm{~m}$ das extremidades para bordadura, restando $3,36 \mathrm{~m}^{2}$ como área útil. Os tratamentos utilizados estão descritos na Tabela 1 . As doses foram parceladas em duas aplicações: a primeira aplicada no estádio V6, e a segunda, aplicada em V8 a V10, 15 dias após a primeira. Foram analisadas as seguintes variáveis de produtividade: altura de plantas (AP), altura de 10 plantas por parcela medindo-se da base da planta (colo) até a inserção do pendão; estimativa de produtividade, milho colhido na área útil da parcela corrigindo-se o teor de água para 13\% (base seca); diâmetro de espiga, obtido com o auxílio do paquímetro, considerando o ponto correspondente ao centro da espiga, de dez espigas por parcela; massa seca de mil grãos (MMG), através de oito subamostras de cem sementes provenientes de cada parcela, de acordo com as Regras para Análise de Sementes (Brasil, 2009). 
Tabela 1. Descrição dos tratamentos utilizados no experimento.

\begin{tabular}{cc}
\hline Tratamentos & Descrição \\
\hline T0 (Controle) & Sem adubação nitrogenada \\
T1 & $75 \mathrm{~kg} \mathrm{ha}^{-1}$ de nitrogênio com ureia comum \\
T2 & $100 \mathrm{~kg} \mathrm{ha}^{-1}$ de nitrogênio com ureia comum \\
T3 & $125 \mathrm{~kg} \mathrm{ha}^{-1}$ de nitrogênio com ureia comum \\
T4 & $75 \mathrm{~kg} \mathrm{ha}^{-1}$ de nitrogênio com ureia peletizada \\
T5 & $100 \mathrm{~kg} \mathrm{ha}^{-1}$ de nitrogênio com ureia peletizada \\
T6 & $125 \mathrm{~kg} \mathrm{ha}^{-1}$ de nitrogênio com ureia peletizada
\end{tabular}

Foi realizada também a avaliação econômica, calculado o faturamento em função apenas das doses e fontes de $\mathrm{N}$ utilizados e a produção obtida. $\mathrm{O}$ levantamento de preços foi realizado em 10/10/2014 em Barreiras/BA, cuja saca $(60 \mathrm{~kg})$ de milho custava $\mathrm{R} \$ 22,00$, e o quilo de ureia comum $\mathrm{R} \$ 1,20$ e de ureia peletizada $\mathrm{R} \$ 1,50$.

Os dados obtidos foram submetidos a análise de variância pelo teste $\mathrm{F}$, para efeito de doses de nitrogênio foram ajustadas equações de regressão que melhor representassem os valores observados, adotando linha de tendência que apresentou melhor ajuste e quando necessário as médias foram comparadas pelo teste de Tukey a 5\% de probabilidade. As análises foram realizadas por meio do software SISVAR (FERREIRA, 2011).

\section{RESULTADOS E DISCUSSÃO}

Não houve diferença estatística significativa na altura de plantas quando comparadas as fontes de nitrogênio utilizadas. As doses de nitrogênio aplicadas influenciaram a altura das plantas de milho, observando respostas positivas até a dose de $75 \mathrm{~kg} \mathrm{ha}^{-1}$ (Figura 2).

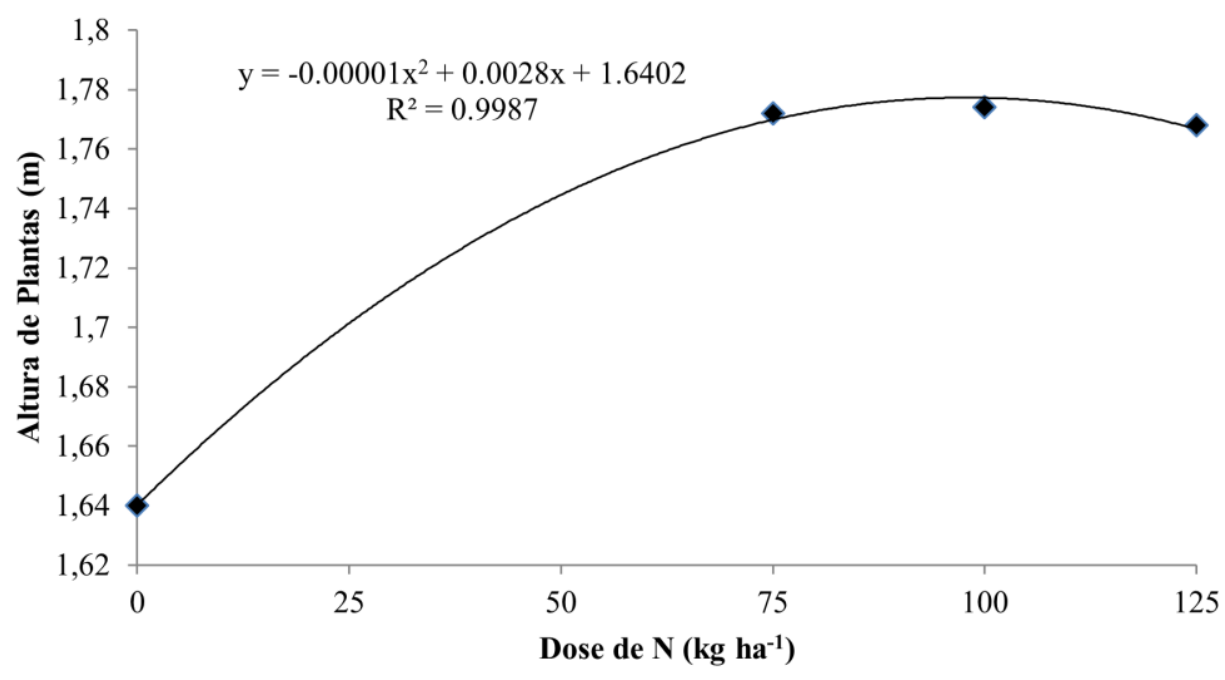

Figura 2: Análise de regressão para o parâmetro altura de plantas em função das doses de nitrogênio aplicadas. 
As fontes nitrogenadas utilizadas também não proporcionaram efeitos sobre o diâmetro de espiga (Figura 3). Características relacionadas a espiga normalmente são fatores ligados ao próprio genótipo (Rotili et al., 2012).

Quando comparada as doses aplicadas, a dose de $100 \mathrm{~kg} \mathrm{ha}^{-1}$ proporcionou o maior diâmetro médio das espigas. Kappes et al. (2014), verificou que o aumento nas doses de nitrogênio proporcionou aumento linear do diâmetro de espiga.

Os resultados diferem do trabalho de Civardi et al. (2011), que observaram aumento no comprimento médio e diâmetro de espigas em decorrência da aplicação de ureia convencional quando comparada com a ureia peletizada.

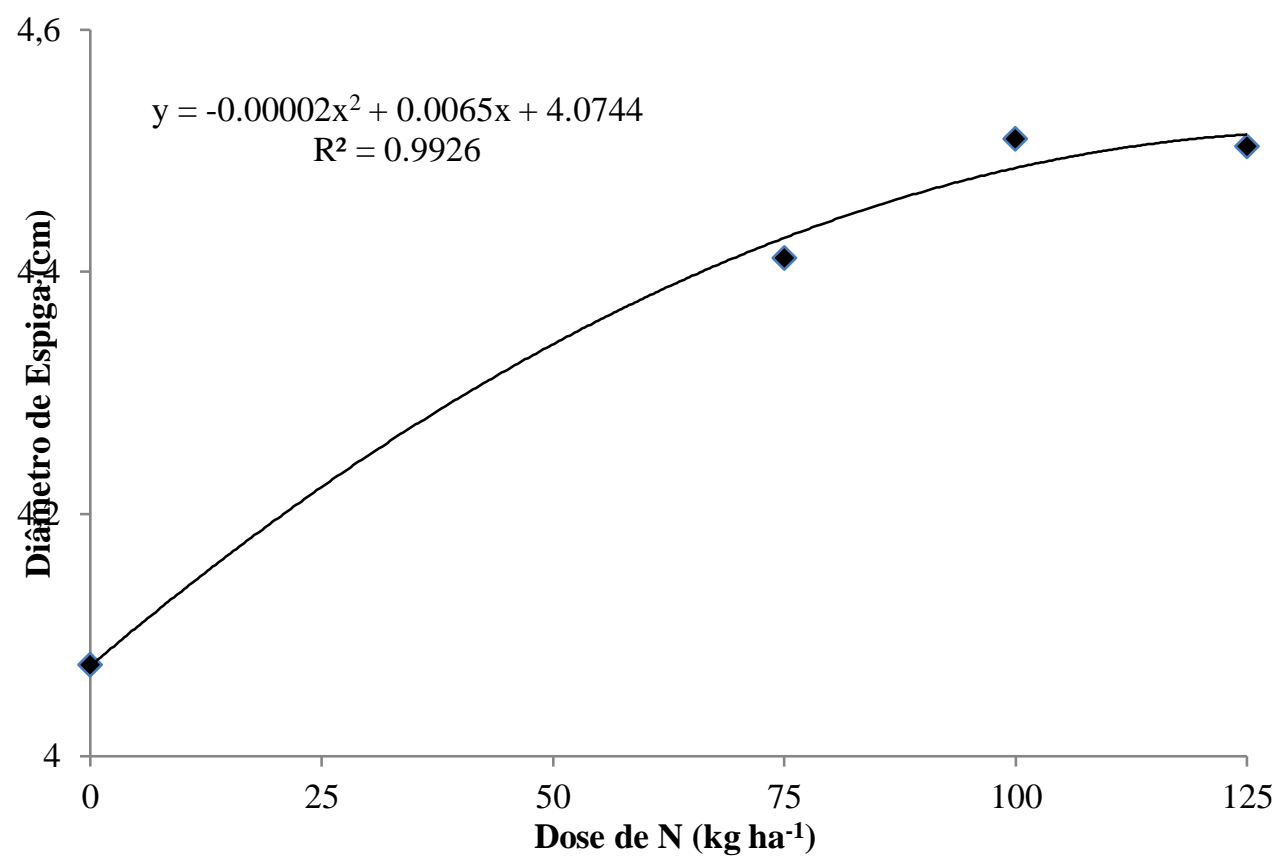

Figura 3: Análise de regressão para o parâmetro diâmetro de espigas em função das doses de nitrogênio aplicadas.

Os resultados observados na avaliação da massa de mil grãos (Tabela 2) mostraram-se significativos ao nível de $5 \%$ de probabilidade quando comparadas às fontes utilizadas, indicando superioridade para a ureia peletizada e não significativos quando comparadas as doses aplicadas. Resultados esses que contrastam com os de Queiroz et al. (2011), que não observaram efeito das diferentes fontes de $\mathrm{N}$ na produção de grãos e na massa de mil grãos, inclusive fertilizantes de liberação gradativa. Valderrama et al. (2011), em trabalho no qual utilizaram diferentes doses de ureia, com e sem revestimento polimerizado, também não encontraram diferença significativa para a variável massa de mil grãos.
A aplicação de doses de $\mathrm{N}$ influenciou a produtividade do milho. A cultura apresentou ganho de forma linear ao aumento da dose de $\mathrm{N}$ aplicado, independente da fonte utilizada (Figura 4).

Isso demonstra a grande capacidade de resposta da cultura ao nitrogênio e o quão importante é este nutriente para os diversos processos bioquímicos da planta. De acordo com o modelo ajustado de produção em função da dose de $\mathrm{N}$, houve incremento de $6,50 \mathrm{~kg} \mathrm{ha}^{-1}$ de milho por cada $\mathrm{kg}$ de $\mathrm{N}$ aplicado. $\mathrm{O}$ que está de acordo com o descrito por Coelho (2008), em que $80 \%$ dos trabalhos realizados avaliando aplicação de doses de $\mathrm{N}$ no milho, a cultura respondeu de forma positiva 
ao aumento da dose, devido ao nutriente ser um dos mais exigidos.

Os dados observados foram semelhantes aos obtidos por Carmo et al., (2012), em que, avaliando diferentes doses e fontes de $\mathrm{N}$, observou diferenças significativas apenas para o fator doses de nitrogênio não verificando influência do fator fontes de $\mathrm{N}$ e da interação entre esses fatores.

Civardi et al. (2011), concluíram que a aplicação de $\mathrm{N}$, na dose de $120 \mathrm{~kg}$. ha ${ }^{-1}$, com ureia comum, propiciou maior rendimento de grãos de milho e maior lucratividade, quando comparada a outras fontes nitrogenadas, como a ureia revestida com polímeros, valores consideravelmente superiores aos encontrados neste trabalho, o que pode estar relacionado a fatores ambientais ocorridos no período do experimento.

.Neumann et al. (2005), relata que a eficiência da adubação nitrogenada depende de diversos fatores, dentre eles, das condições climáticas, tipo de solo e capacidade de extração da cultura, sendo as condições ambientais o principal fator para este trabalho uma vez que, o longo período de estiagem pode ter influenciado nas transformações do $\mathrm{N}$ no solo e na sua absorção pela planta.

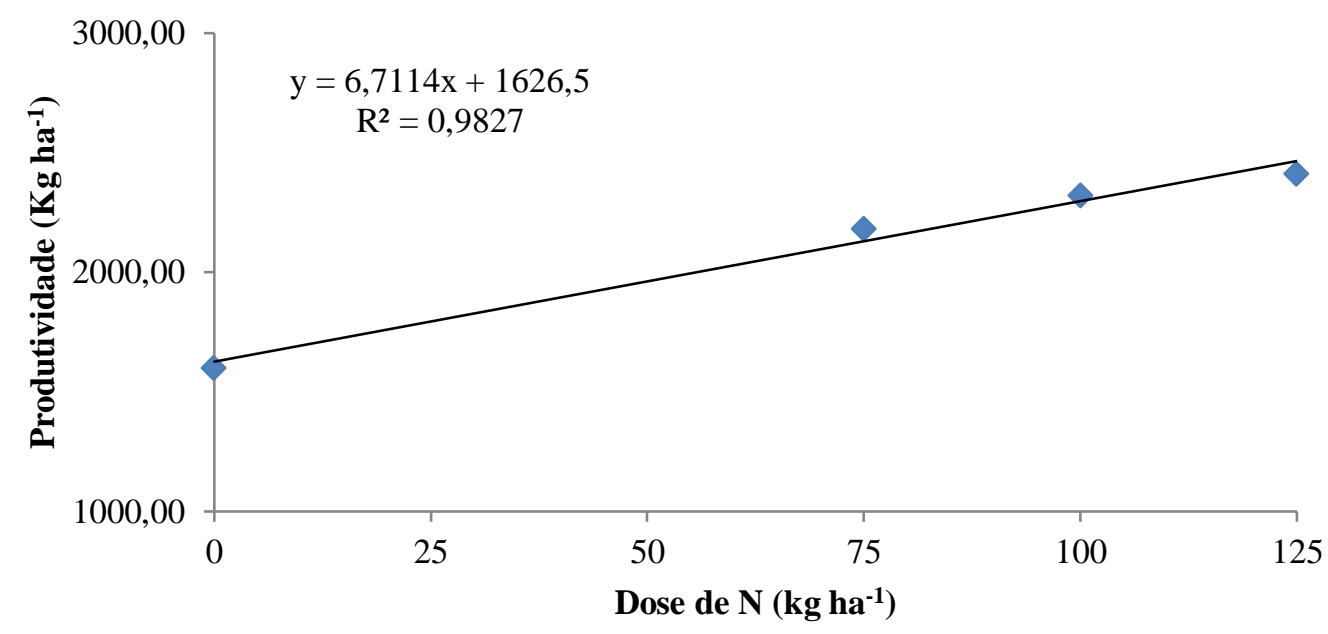

Figura 4: Análise de regressão para o parâmetro produtividade em função das doses de $\mathrm{N}$ aplicadas.

Tabela 2: Comparação das medias do fator 1 (fontes de ureia) e fator 2 (doses aplicadas), pelo teste de Tukey ao nível de 5\% de probabilidade para variável massa de mil grãos.

\begin{tabular}{cc}
\hline \multicolumn{3}{c}{ Médias dos Fatores* } \\
\hline \multicolumn{1}{c}{ Fonte } \\
\hline Ureia comum & $31,51 \mathrm{~b}$ \\
Ureia Peletizada & $35,27 \mathrm{a}$ \\
\hline $\mathrm{dms}=$ & 2,27 \\
\hline & \\
\hline Dose $1\left(75 \mathrm{~kg} \mathrm{ha}^{-1}\right)$ & $32,72 \mathrm{a}$ \\
Dose $2\left(100 \mathrm{~kg} \mathrm{ha}^{-1}\right)$ & $33,11 \mathrm{a}$ \\
Dose $3\left(125 \mathrm{~kg} \mathrm{ha}^{-1}\right)$ & $34,34 \mathrm{a}$ \\
\hline $\mathrm{dms}=$ & 3,37 \\
\hline
\end{tabular}

*As médias seguidas pelas mesmas letras não diferem entre si. 
De acordo com os resultados (Tabela 3), a dose de $75 \mathrm{~kg} \mathrm{ha}^{-1}$ de ureia comum, apresentou o melhor retorno financeiro ( $\mathrm{R} \$$ 607,23). Essa afirmativa é constatada pelos valores da diferença do retorno financeiro em função das doses em que o aumento relativo foi observado até a dose de $75 \mathrm{~kg}$ $\mathrm{ha}^{-1}$ para a ureia comum.

Segundo Queiroz et al. (2011), quando não for encontrado diferenças em produtividade em relação as fontes de ureia utilizadas, a melhor opção para utilização pelo produtor será a ureia convencional, uma vez que apresenta o menor custo por $\mathrm{kg}$ de $\mathrm{N}$ aplicado.
A partir da dose de $75 \mathrm{~kg} \mathrm{ha}^{-1}$, houve decréscimo no retorno, já que a dose máxima de 125 $\mathrm{kg} \mathrm{ha}^{-1}$ apresentou retorno de $\mathrm{R} \$ 558,73$ e $\mathrm{R} \$ 461,92$ para a ureia comum e ureia peletizada, respectivamente. De certa forma, sabe-se que a administração da empresa rural leva em análise diversos outros custos de produção que vão além da cotação do fertilizante e da produção obtida que não foram mensurados neste trabalho, mas que servem como base para a pesquisa.

Tabela 3. Análise da viabilidade econômica da ureia comum e ureia revestida na produção de milho no Oeste da Bahia.

\begin{tabular}{|c|c|c|c|c|c|c|c|c|}
\hline \multirow{2}{*}{$\begin{array}{c}\text { Dose de N } \\
\left(\mathrm{Kg} \mathrm{ha}^{-1}\right)\end{array}$} & \multicolumn{2}{|c|}{ Produção (Kg ha-1) } & \multicolumn{2}{|c|}{ Faturamento (R\$/ha) } & \multicolumn{2}{|c|}{$\begin{array}{c}\text { Investimento em } \\
\text { adubos }\end{array}$} & \multicolumn{2}{|c|}{ Retorno (R\$/ha) } \\
\hline & $\mathbf{U C}$ & UP & $\mathbf{U C}$ & UP & $\mathbf{U C}$ & UP & $\mathbf{U C}$ & $\mathbf{U P}$ \\
\hline 0 & 1600 & 1600 & 586,67 & 586,67 & 0 & 0 & 586,67 & 586,67 \\
\hline 75 & 2201 & 2167 & 807,03 & 794,57 & 199.8 & 249.75 & 607,23 & 544,82 \\
\hline 100 & 2190 & 2454 & 803,00 & 899,8 & 266.4 & 333 & 536,6 & 566,8 \\
\hline 125 & 2432 & 2395 & 891,73 & 878,17 & 333 & 416.25 & 558,73 & 461,92 \\
\hline
\end{tabular}

UC: Ureia Comum. UP: Ureia peletizada. Saca $(60 \mathrm{Kg})$ de milho, comercializada em Barreiras/BA a R\$ 22,00. Ureia comum e peletizada a $R \$ 1,20$ e 1,50, respectivamente. Retorno: diferença entre o faturamento e o investimento em adubos. Levantamento feito em 05/12/2014.

\section{CONCLUSÃO}

Diante dos resultados observados a dose de $75 \mathrm{~kg} \mathrm{ha}^{-1}$ de ureia comum mostrou-se satisfatória para as características agronômicas de produtividade e viável economicamente quando comparada à ureia peletizada nas condições ambientais avaliadas nesse experimento.

\section{REFERÊNCIAS BIBLIOGRÁFICAS}

Brasil, Ministério da Agricultura e Reforma Agrária (2009). Regras para análise de sementes. Brasília, DF, Secretaria Nacional de Defesa Agropecuária. Departamento Nacional de Defesa Vegetal. Coordenação de Laboratório Vegetal.
Carmo, M. S.; Cruz, S. C. S.; Souza, E. J.; Campos, L. F. C.; Machado, C. G. (2012). Doses e fontes de nitrogênio no desenvolvimento e produtividade da cultura de milho doce (Zea mays convar. Saccharata var. rugosa). Bioscience Journal 28: 223-231.

Civardi, E. A.; Silveira Neto, A. N.; Ragagnin, V. A.; Godoy, E. R.; Brod, E. (2011). Ureia de libração lenta aplicada superficialmente e ureia comum incorporada ao solo no rendimento do milho. Pesquisa Agropecuária Tropical 41(1): 5259. https://doi.org/10.5216/pat.v41i1.8146

Coelho, A. M. (2008). Adubação e nutrição do milho. In: Cruz, J. C.; Karam, D.; Monteiro, M. A. R.; Magalhaes, P. C. (Ed.). A cultura do milho. $1^{\circ}$ 
ed. Sete Lagoas: Embrapa Milho e Sorgo, 2008. p. 131-157.

Conab - Companhia Nacional de Abastecimento. Acompanhamento da safra Brasileira - grãos safra 2019/2020 - v. 7 - Quarto levantamento. Brasília: MAPA, 2020. P. 1-104.

Costa, N. R.; Andreotti, M.; Gameiro, R. A.; Pariz, C. M.; Buzetti, S.; Lopes, K. S. M. (2012). Adubação nitrogenada no consórcio de milho com duas espécies de braquiária em sistema plantio direto. Pesquisa Agropecuária Brasileira, 47(8): 1038-1047.

Embrapa. Sistema brasileiro de classificação de solos. $5^{a}$ ed. Brasília, DF: Embrapa, 2018, 356p.

Fageria, N. K.; Santos, A. B.; Cutrim, V. A. (2007). Produtividade de arroz irrigado e eficiência de uso do nitrogênio influenciadas pela fertilização nitrogenada. Pesquisa Agropecuária Brasileira 42(07): 1029-1034.

Ferreira, D. F. (2011). Sisvar: a computer statistical analysis system. Ciência e Agrotecnologia 35(6): 1039-1042.

Frazão, Joaquim J.; Silva, A. R.; Silva, V. L.; Oliveira, V. A.; Corrêa, R. S. (2014) Fertilizantes nitrogenados de eficiência aumentada e ureia na cultura do milho. Revista Brasileira de Engenharia Agrícola e Ambiental 18(12): 1262-1267. https://doi.org/10.1590/18071929/agriambi.v18n12p1262-1267

Kappes, C.; Arf, O.; Bem, E. A. D.; Portugal, J. R.; Gonzaga, A. R. (2014). Manejo do nitrogênio em cobertura na cultura do milho em sistema plantio direto. Revista Brasileira de Milho e Sorgo 13(2): 201-217. https://doi.org/10.18512/19806477/rbms.v13n2p201-217

Neumann, M.; Sandini, I. E.; Lustosa, S. B. C.; Ost, P. R.; Romano, M. A.; Falbo, M. K.; Pansera, E. R. (2005) Rendimentos e componentes de produção da planta de milho (Zea mays L.) Para silagem, em função de níveis de adubação nitrogenada em cobertura. Revista Brasileira de Milho e Sorgo 4(3): 418-427.
Queiroz, A. M.; Souza, C. H. E.; Machado, V. J.; Lana, R. M. Q.; Korndorfer, G. H.; Silva, A. A. (2011). Avaliação de diferentes fontes e doses de nitrogênio na adubação da cultura do milho (Zea mays L.). Revista Brasileira de Milho e Sorgo 10(3): 257-266. https://doi.org/10.18512/19806477/rbms.v10n3p257-266

Rotili, E. A.; Cancellier, L. L.; Dotto, M. A.; Peluzio, J. M.; Carvalho, E. V. (2012). Divergência genética em genótipos de milho, no estado do Tocantins. Revista Ciência Agronômica, 43(3): 516-521. https://dx.doi.org/10.1590/S180666902012000300014

Sangoi, L.; Silva, P. R. F., Argenta, G.; Rambo, L. (2010). Ecofisiologia da cultura do milho para altos rendimentos. Lages: Graphel. 87p.

Sangoi, L.; Schmitt, A.; Vieira, J.; Picoli Junior. G. J.; Souza, C. A.; Casa, R. T.; Schenatto, D. E.; Giordani, W.; Boniatti, C. M.; Machado, G. C.; Horn, D. (2012). Variabilidade na distribuição espacial de plantas na linha e rendimento de grãos de milho. Revista Brasileira de Milho e Sorgo 11(3): 268-277. $\quad$ http://dx.doi.org/10.18512/19806477/rbms.v11n3p268-277

Silva, A. A.; Silva, T. S.; Vasconcelos, A. C. P.; Lana, R. M. Q. (2012). Aplicação de diferentes fontes de ureia de liberação gradual na cultura do milho. Bioscience Journal 28(1): 140-111.

Souza, D.M.G.; Lobato, E., eds. (2004). Cerrado: Correção do solo e adubação. Planaltina, Embrapa Cerrados, 416p.

Souza, P. M.; Braga, M. J. (2004). Aspectos econômicos da produção e comercialização do milho no Brasil. In: Galvão, J. C. C.; Miranda, G. V. (Ed.). Tecnologia de Produção de Milho. Viçosa: UFV. p.13-54.

Valderrama, M.; Buzetti, S.; Benett, C. G. S.; Andreotti, M.; Teixeira Filho, M. C. M. (2011). Fontes e doses de NPK em milho irrigado sob plantio direto. Pesquisa Agropecuária Tropical 41(2): 254-263. 